\title{
QUANTITATION OF ANTICANCER DRUGS - CYCLOPHOSPHAMIDE AND IFOSFAMIDE IN URINE AND WATER SEWAGE SAMPLES BY GAS CHROMATOGRAPHY-MASS SPECTROMETRY
}

\author{
VEERAVAN LEKSKULCHAI \\ Srinakharinwirot University, Bangkok, Thailand \\ Faculty of Medicine, Department of Pathology
}

\begin{abstract}
Objectives: Cyclophosphamide (CP) and ifosfamide (IF) are effective anti-cancer drugs but their genotoxicity can harm everyone contacting them occupationally or environmentally. Therefore, a sensitive method for monitoring their amounts in biological and environmental samples is needed. This has aimed to develop a method for analyzing these drugs in urine and water sewage samples. Material and Methods: The drug spiked samples were extracted, derivatized, and analyzed by gas chromatography-mass spectrometry and the analytical parameters were validated. Results: The method gave linear calibration curves at the concentrations of $0-190 \mathrm{nmol} / \mathrm{l}$. It had the quantitation limit of $3.8 \mathrm{nmol} / \mathrm{l}$ and showed acceptable specificity, accuracy, recovery and precision. Conclusions: The developed method can be used reliably for monitoring CP and IF concentrations in urine and water sewage. The method will be applied for preventing health risk from occupational and environmental exposures to these drugs. Int J Occup Med Environ Health 2016;29(5):815-822
\end{abstract}

Key words:

Environment, Cyclophosphamide, Antineoplastic agents, Gas chromatography-mass spectrometry, Ifosfamide, Sensitive and specificity

\section{INTRODUCTION}

Cyclophosphamide (CP) and ifosfamide (IF) are alkylating agents commonly used to treat various cancers. However, their cytotoxic effects are not specific towards cancer cells, they harm normal cells causing life threatening adverse effects, including cancer, particularly CP has been classified as a human carcinogen [1], and the case of pregnant women these drugs can be teratogenic and fetotoxic [2-4]. Their toxicities have been reported not only the case of patients but also the case of health care workers occupationally contacting them [5-8].
Recently, the environmental contamination by these drugs from patient excretions and hospital waste products have raised concern [9-10]. Consequently, their concentrations in biological specimens and environment need to be monitored for health safety. Several methods have been developed for quantitation of these drugs; however, the best is liquid chromatography-mass spectrometry (LC-MS) [11-13] or liquid chromatography-tandem mass spectrometry (LCMS/MS) [14,15], which were not available in our laboratory. The gas chromatography methods have been reported with

Received: August 20, 2015. Accepted: November 17, 2015.

Corresponding author: V. Lekskulchai, Srinakharinwirot University, Faculty of Medicine, Department of Pathology, 114 Sukhumvit 23, Wattana, Bangkok 10110, Thailand (e-mail: veeravah@swu.ac.th). 
and without derivatizations [16-19] but mostly showed low sensitivity which might be not suitable for preventive purposes. In this presentation, poor chromatographic behaviors of $\mathrm{CP}$ and IF have been revealed. The main goal of this study has been to develop a gas chromatography-mass spectrometry method for reliably measuring $\mathrm{CP}$ and IF concentrations in urine of people occupationally exposed to these drugs and in water sewage from environments expected to be contaminated by CP or IF.

\section{MATERIAL AND METHODS}

\section{Chemicals and reagents}

Cyclophosphamide monohydrate, ifosfamide, heptafluorobutylic anhydride (HFBA), and trifluoroacetic anhydride (TFAA) were purchased from Sigma-Aldrich chemical company (St. Louis, Missouri, USA). Cyclophosphamide-d4 and ifosfamide-d4 were obtained from Toronto Research Chemical Inc. (Ontario, Canada). The other solvents and chemicals were of analytical grade and were purchased from Merck KGaA (Darmstadt, Germany).

\section{Instrumental conditions}

The analyses were performed on 6890 gas chromatograph equipped with 5973N mass spectrometer and 7683 automatic liquid sampler (Agilent Technologies, USA). The Agilent MSD ChemStation software system and the National Institute of Standards and Technology (NIST) software system of MS library and chemical structures (software registration number $\mathrm{BN} 36 \mathrm{CCD} 7 \mathrm{AD}$ and $\mathrm{BN}$ 35EACB87) on a personal computer were used to operate the instrument and to acquire data. Separation was carried out on a HP-5MS capillary column (J\&W Scientific, USA). The initial oven temperature was set at $70^{\circ} \mathrm{C}$ for $1 \mathrm{~min}$, and ramped to $250^{\circ} \mathrm{C}$ at a rate of $10^{\circ} \mathrm{C} / \mathrm{min}$. The final temperature was held for $1 \mathrm{~min}$. For TFAA or HFBA derivatives, the initial oven temperature was set at $70^{\circ} \mathrm{C}$ for $1 \mathrm{~min}$; then increased to $200^{\circ} \mathrm{C}$ at the rate of $10^{\circ} \mathrm{C} / \mathrm{min}$ and to $240^{\circ} \mathrm{C}$ at the rate of $20^{\circ} \mathrm{C} / \mathrm{min}$. The final temperature was held for $1 \mathrm{~min}$.

\section{Sample preparation}

The stock standard solutions $(0.383 \mathrm{mmol} / \mathrm{l})$ were prepared in methanol. Drug-free urine samples were collected from a healthy volunteer, centrifuged and pooled in a clean bottle. Five water sewage samples were collected from 5 different residential areas in Bangkok, located far away from health care centers. Water sewages were centrifuged and their sediments were discarded. Control samples and working standard solutions were prepared by adding the stock standard solution in urine to a certain concentration. Likewise, water sewages were spiked with the stock standard solution to a given concentration. The sample extraction was performed as indicated in the diagram below (Figure 1 ).

The CP- $\mathrm{d}_{4}$ and IF- $\mathrm{d}_{4}$ standard solutions $(0.383 \mathrm{mmol} / \mathrm{l})$ were used as the internal standards. Twenty $\mu$ l of the internal standard were added into the sample prior to extraction and derivatization with TFAA. Trifluoroacetic anhydride derivatives of CP (TFA-CP) and IF (TFA-IF) were quantitated in selective ion monitoring (SIM) mode, the mass qualifier ions for TFA-CP were selected at the $\mathrm{m} / \mathrm{z} 212, \mathrm{~m} / \mathrm{z} 150$ and $\mathrm{m} / \mathrm{z}$ 136, with $\mathrm{m} / \mathrm{z} 307$ being the quantifier ion; the qualifier ions for

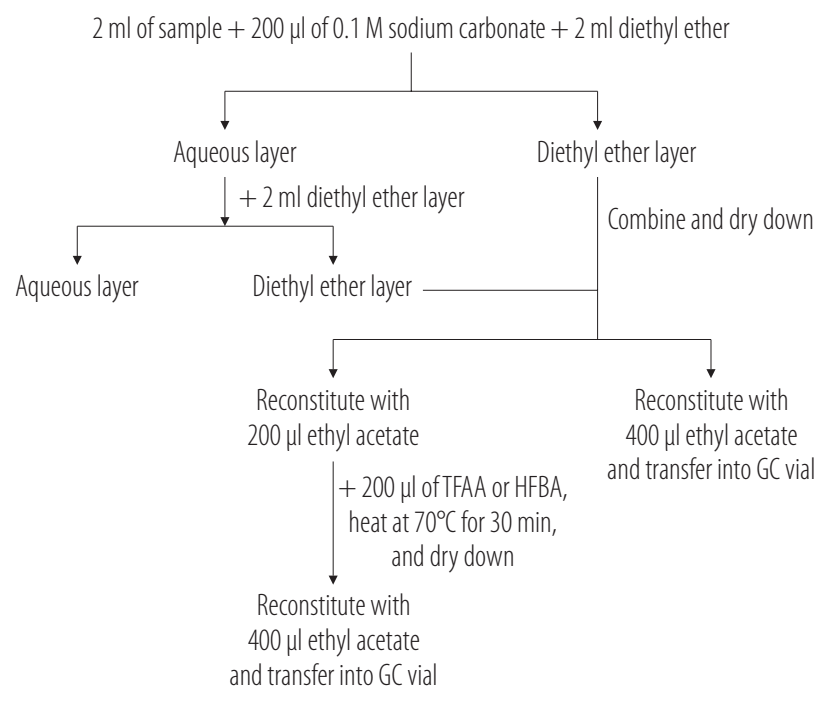

TFAA - trifluoroacetic anhydride; HFBA - heptafluorobutylic anhydride; GC - gas chromatography.

Fig. 1. Sample extraction and derivatization 
TFA-IF were selected at the $\mathrm{m} / \mathrm{z}$ 150, m/z 212 and m/z 181, with $\mathrm{m} / \mathrm{z} 307$ being the quantifier ion. The selected quantifier ions for TFA-CP- $\mathrm{d}_{4}$ and TFA-IF- $\mathrm{d}_{4}$ were at the m/z 311. All calculations were based on peak area ratios.

\section{Method validation}

The limit of detection was the lowest concentration of CP or IF correctly identified by NIST. The linearity was expressed as linear regression of the calibration curves. The limit of quantitation was the lowest concentration of drug giving measured results close to the added amount with the signal to noise ratio of 5:1. The accuracy and extraction recovery were determined by analyzed control samples at each concentration 5 times. Accuracy was indicated by averaging the percentages of differences between the measured value and the added concentration. The within-day and between-day precision were determined by analyzing 10 control samples of each concentration within the same day and in 10 consecutive days. The recovery and precision were expressed in mean \pm uncertainty $(\mathrm{U})$ at $95 \%$ confidence interval $(\mathrm{CI})$; the coverage factor $(\mathrm{k})=2$ [20]. Statistical analysis was performed using SPSS IBM Singapore Pte Ltd. (registration No. 1975-01566-C).

\section{RESULTS}

As shown in Figure 2, CP gave 2 separated peaks which were identified by NIST as (-)-cyclophosphamide.

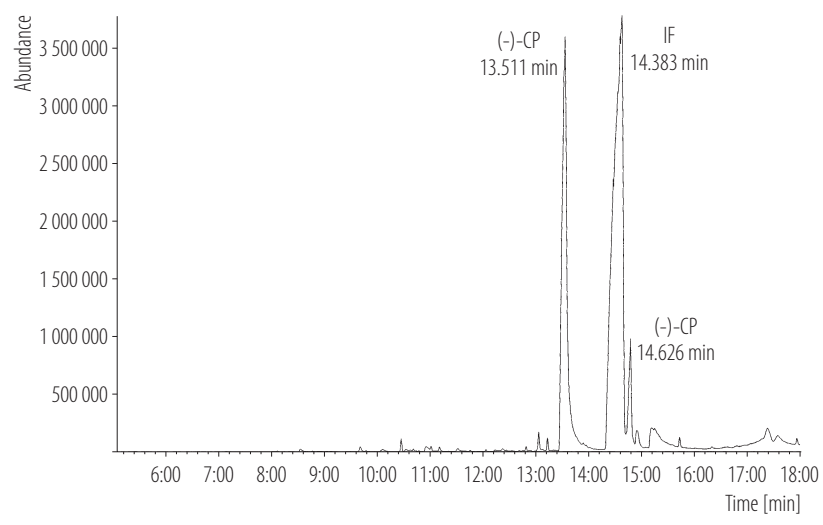

Fig. 2. Total ion chromatograms of cyclophosphamide (CP) and ifosfamide (IF)
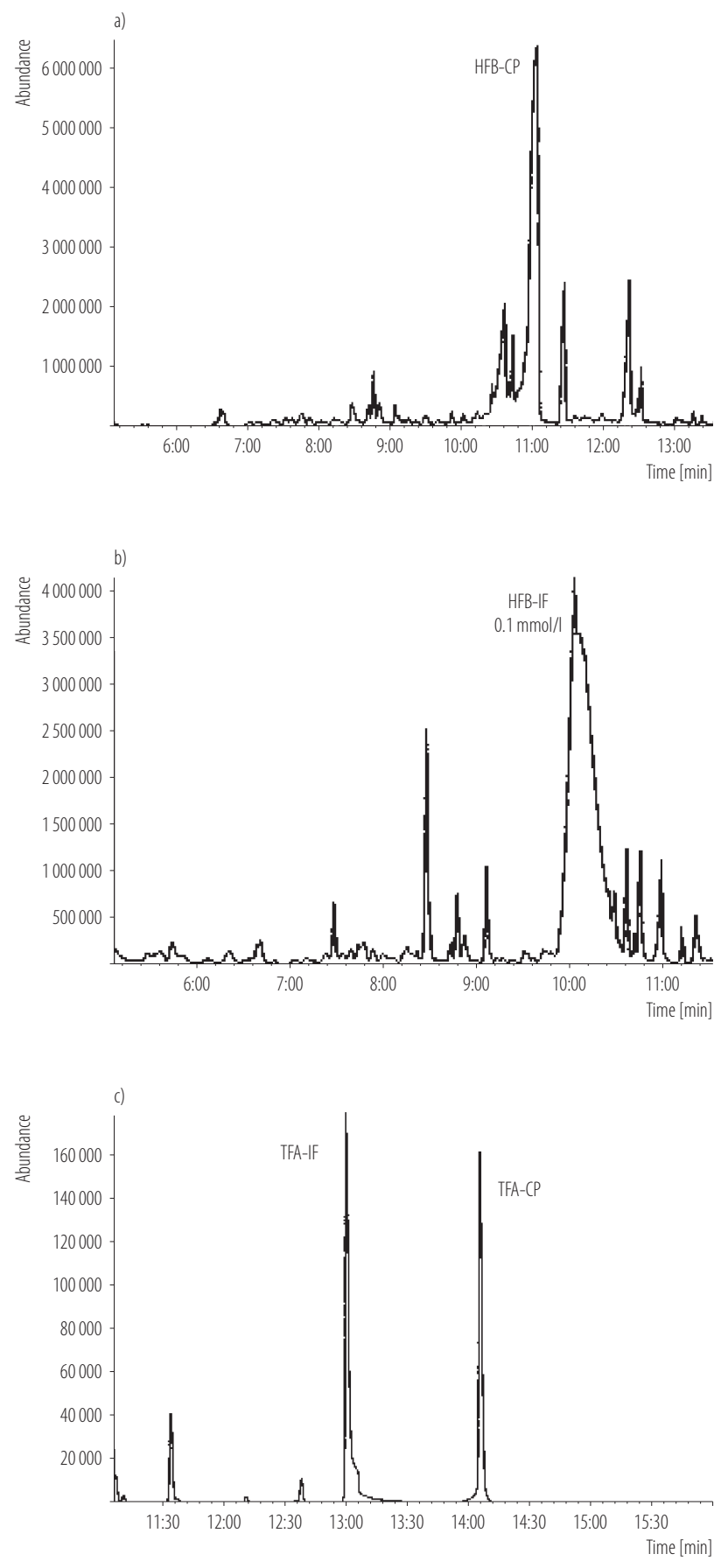

HFB-CP - HFBA derivative of CP; HFB-IF - HFBA derivative of IF; TFA-IF - TFAA derivative of IF; TFA-CP - TFAA derivative of CP.

Fig. 3. Total ion chromatograms of heptafluorobutylic anhydride (HFBA) derivatives of a) cyclophosphamide (CP) and b) ifosfamide (IF), and c) trifluoroacetic anhydride (TFAA) derivatives of CP and IF 
Table 1. Accuracy, recovery and precision of the gas chromatography-mass spectrometry in analyses of CP and IF in urine and water sewages

\begin{tabular}{|c|c|c|c|c|c|}
\hline \multirow{2}{*}{$\begin{array}{l}\text { Drug spiked } \\
\text { sample }\end{array}$} & \multirow{2}{*}{$\begin{array}{c}\text { Added } \\
\text { concentration } \\
{[\mathrm{nmol} / \mathrm{l}]}\end{array}$} & \multirow{2}{*}{$\begin{array}{c}\text { Accuracy } \\
\text { (M of \% differences) } \\
(\mathrm{N}=5)\end{array}$} & \multirow{2}{*}{$\begin{array}{l}\text { Recovery } \\
\left(\mathrm{M} \pm \mathrm{U}_{\mathrm{r}}\right) \\
{[\mathrm{nmol} / \mathrm{l}]} \\
(\mathrm{N}=5)\end{array}$} & \multicolumn{2}{|c|}{$\begin{array}{c}\text { Precision } \\
\left(\mathrm{M} \pm \mathrm{U}_{\mathrm{p}}\right) \\
{[\mathrm{nmol} / \mathrm{l}]}\end{array}$} \\
\hline & & & & $\begin{array}{c}\text { within-day } \\
(\mathrm{N}=10)\end{array}$ & $\begin{array}{c}\text { between-day } \\
(\mathrm{N}=10)\end{array}$ \\
\hline \multicolumn{6}{|l|}{$\mathrm{CP}$} \\
\hline \multirow[t]{3}{*}{ urine } & 0 & & 0 & 0 & 0 \\
\hline & 9.5 & 104 & $9.88 \pm 1.422$ & $9.31 \pm 0.380$ & $9.50 \pm 0.567$ \\
\hline & 38.0 & 102 & $38.76 \pm 3.723$ & $38.32 \pm 1.134$ & $38.71 \pm 1.964$ \\
\hline \multirow[t]{3}{*}{ water 1} & 0 & & 0 & & \\
\hline & 9.5 & 100 & $9.50 \pm 1.202$ & & \\
\hline & 38.0 & 106 & $40.28 \pm 3.875$ & & \\
\hline \multirow[t]{3}{*}{ water 2} & 0 & & 0 & & \\
\hline & 9.5 & 96 & $9.12 \pm 1.427$ & & \\
\hline & 38.0 & 104 & $39.52 \pm 3.886$ & & \\
\hline \multirow[t]{3}{*}{ water 3} & 0 & & 0 & & \\
\hline & 9.5 & 104 & $9.88 \pm 1.590$ & & \\
\hline & 38.0 & 110 & $41.80 \pm 2.687$ & & \\
\hline \multirow[t]{3}{*}{ water 4} & 0 & & 0 & & \\
\hline & 9.5 & 96 & $9.12 \pm 1.599$ & & \\
\hline & 38.0 & 102 & $38.76 \pm 4.432$ & & \\
\hline \multirow[t]{3}{*}{ water 5} & 0 & & 0 & & \\
\hline & 9.5 & 104 & $9.88 \pm 1.565$ & & \\
\hline & 38.0 & 104 & $39.52 \pm 3.875$ & & \\
\hline \multicolumn{6}{|l|}{ IF } \\
\hline \multirow[t]{3}{*}{ urine } & 0 & & 0 & 0 & 0 \\
\hline & 9.5 & 104 & $9.88 \pm 1.587$ & $9.12 \pm 0.507$ & $9.69 \pm 0.683$ \\
\hline & 38.0 & 104 & $39.52 \pm 5.098$ & $37.62 \pm 0.761$ & $38.11 \pm 1.964$ \\
\hline \multirow[t]{3}{*}{ water 1} & 0 & & 0 & & \\
\hline & 9.5 & 104 & $9.88 \pm 1.423$ & & \\
\hline & 38.0 & 108 & $41.04 \pm 4.954$ & & \\
\hline \multirow[t]{3}{*}{ water 2} & 0 & & 0 & & \\
\hline & 9.5 & 104 & $9.98 \pm 1.428$ & & \\
\hline & 38.0 & 106 & $40.28 \pm 4.333$ & & \\
\hline \multirow[t]{3}{*}{ water 3} & 0 & & 0 & & \\
\hline & 9.5 & 104 & $1.03 \pm 1.873$ & & \\
\hline & 38.0 & 102 & $38.76 \pm 3.723$ & & \\
\hline
\end{tabular}


Table 1. Accuracy, recovery and precision of the gas chromatography-mass spectrometry in analyses of $\mathrm{CP}$ and IF in urine and water sewages - cont.

\begin{tabular}{|c|c|c|c|c|c|}
\hline \multirow{2}{*}{$\begin{array}{l}\text { Drug spiked } \\
\text { sample }\end{array}$} & \multirow{2}{*}{$\begin{array}{c}\text { Added } \\
\text { concentration } \\
{[\mathrm{nmol} / \mathrm{l}]}\end{array}$} & \multirow{2}{*}{$\begin{array}{c}\text { Accuracy } \\
\text { (M of \% differences) } \\
(\mathrm{N}=5)\end{array}$} & \multirow{2}{*}{$\begin{array}{l}\text { Recovery } \\
\left(\mathrm{M} \pm \mathrm{U}_{\mathrm{r}}\right) \\
{[\mathrm{nmol} / 1]} \\
(\mathrm{N}=5)\end{array}$} & \multicolumn{2}{|c|}{$\begin{array}{l}\text { Precision } \\
\left(\mathrm{M} \pm \mathrm{U}_{\mathrm{p}}\right) \\
{[\mathrm{nmol} / \mathrm{l}]}\end{array}$} \\
\hline & & & & $\begin{array}{c}\text { within-day } \\
(\mathrm{N}=10)\end{array}$ & $\begin{array}{c}\text { between-day } \\
(\mathrm{N}=10)\end{array}$ \\
\hline \multicolumn{6}{|l|}{ IF - cont. } \\
\hline \multirow[t]{3}{*}{ water 4} & 0 & & 0 & & \\
\hline & 9.5 & 108 & $10.26 \pm 1.520$ & & \\
\hline & 38.0 & 108 & $41.04 \pm 3.723$ & & \\
\hline \multirow[t]{3}{*}{ water 5} & 0 & & 0 & & \\
\hline & 9.5 & 96 & $9.12 \pm 1.414$ & & \\
\hline & 38.0 & 98 & $37.24 \pm 4.465$ & & \\
\hline
\end{tabular}

$\mathrm{CP}$ - cyclophosphamide; IF - ifosfamide; $\mathrm{M}$ - mean; $\mathrm{N}$ - number of analyzed samples; $\mathrm{U}_{\mathrm{r}}$ - expanded uncertainty for extraction recovery; $\mathrm{U}_{\mathrm{p}}$ - expanded uncertainty for precision.

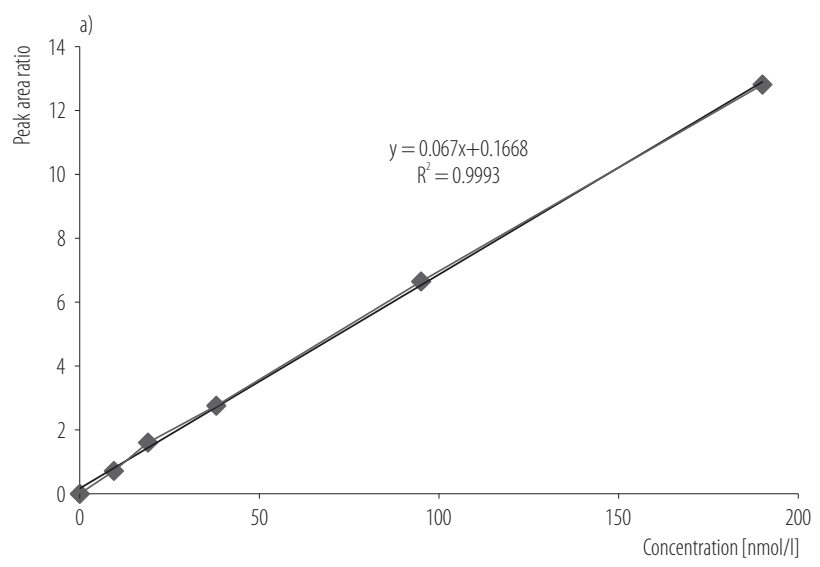

The IF peak was between these peaks. The chromatograms of HFBA derivatives showed high baseline noise (Figure 3). The peaks of TFA-CP and TFA-IF were well separated and low baseline noise was on the chromatogram (Figure 3). The calibration curves of both $\mathrm{CP}$ and IF were linear and passed zero with the $\mathrm{R}^{2}=0.9993$ and 0.9995 , respectively (Figure 4). Drug-free urine samples were triple analyzed and no CP or IF peak was found. Figure 4 demonstrates the calibration curves of $\mathrm{CP}$ and IF

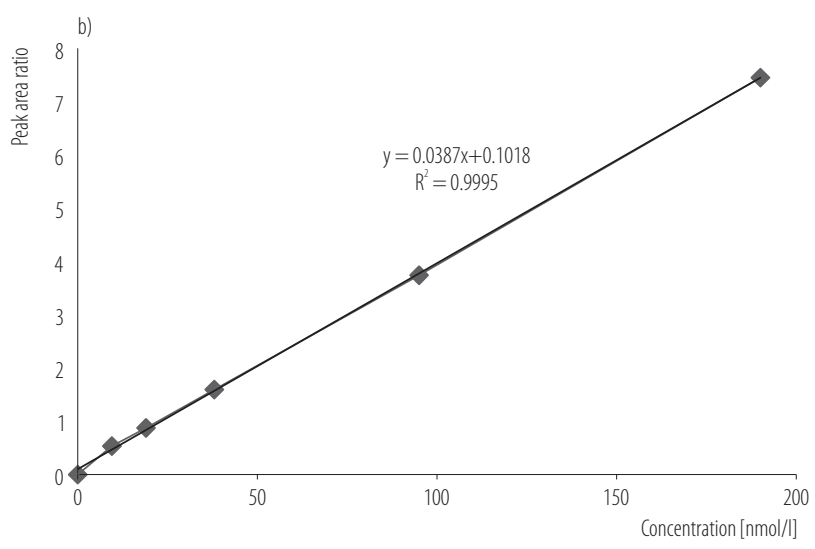
after derivatization with TFAA. The results from method validation are shown in Table 1.

\section{DISCUSSION}

According to previous reports [18,19], CP always gave 2 separated peaks on the chromatogram (Figure 2). The ratios of these 2 peaks were indeed inconsistent causing inaccurate quantitation. Though IF gave a single peak, its detection limit was equal to that of $\mathrm{CP}$ or at $380 \mathrm{nmol} / \mathrm{l}$. Without derivatization, both $\mathrm{CP}$ and IF were poorly detected, possibly due to their low volatility, leading to ion

Fig. 4. Calibration curves of a) cyclophosphamide (CP) and b) ifosfamide (IF) after derivatization with trifluoroacetic anhydride (TFAA) suppression, i.e., reducing droplet formation, which in turn decreased the amount of charged ions in the gas 
phase reaching the mass spectrometer [21]. The drug-free urine gave no detectable $\mathrm{CP}$ and IF peaks indicating high specificity.

As identified by NIST, the undesired peaks on the chromatograms of HFBA derivatives of CP (HFB-CP) and IF (HFB-IF) resulted from the column bleed (Figure 3). The samples were dried down after derivatization as recommended [22,23], but the column bleed revealed that remaining HFBA was not completely removed. Additionally, the peak of HFB-IF was aberrant, having long back tail. As reported [24], HFB-IF may have non-specific adsorption or interaction with the stationary phase leading to gradual elution. Because of the high baseline noise and the aberration of HFB-IF peak, the HFBA derivatization should not be a practical method for CP and IF quantitation either.

Trifluoroacetic anhydride derivatization obviously improved chromatographic behaviors of $\mathrm{CP}$ and IF. Both TFA-CP and TFA-IF presented a single sharp peak with high signal to noise ratios. Trifluoroacetic anhydride derivative of IF was well separated from the TFA-CP (Figure 3). Trifluoroacetic anhydride derivatization also enhanced the MS detection, supporting it to be a practical chemical derivatization for quantitation of $\mathrm{CP}$ and IF.

Drug-spiked plasma samples were studied but no studied solvent could well extract CP and IF from the plasma matrix. Urine and water sewage had similar matrix effect and could be extracted well with the propose procedure. An advantage of collecting urine from non-currently ill person is that an individual will willingly give his/her urine any time requested. Water sewage especially nearby a hospital or pharmaceutical plant is likely a source of these drugs derived from accumulating patient excretion and wastes, therefore, it should be a proper sample for monitoring the environmental contamination of these drugs.

The concentrations of CP and IF were determined after derivatization with TFAA. Their calibration curves passed the zero and were linear at the concentrations ranging from 0 to $190 \mathrm{nmol} / \mathrm{l}$ (Figure 4). The limits of quantitation of both drugs were $3.8 \mathrm{nmol} / \mathrm{l}$. The formerly reported concentrations of these drugs in workers' urine were lower than $3.8 \mathrm{nmol} / 1$ [25,26]. Therefore, the proposed method may give a false negative result in these cases.

Because $\mathrm{CP}$ and IF are genotoxic, they have zero tolerance or no threshold level. By the meaning of zero tolerance, it should not be implied that their concentrations must be zero for health risk prevention. In fact, their adverse effects result from their accumulation in the body to the toxic levels, thus, the proposed method is still expected to be useful for prevention their toxicity in a healthy person. With its acceptable analytical parameters, the method will be further applied for monitoring CP and IF concentrations in urine and water sewage to prevent their adverse effects in occupationally and environmentally exposed people.

\section{CONCLUSIONS}

Demand for CP and IF analysis not only for therapeutic drug monitoring but also for prevention of occupational and environmental pollution is increasing despite the limitation of the available instrument. Chemical and physical properties of CP and IF are responsible for their poor chromatographic behaviors and quantitative parameters. This presentation supports the conclusion of the previous works that TFAA derivatization can improve the chromatographic behavior, molecular stability, and mass spectral detection of CP and IF. Using their stable isotope analogs as the internal standard could improve the analytical recovery, accuracy, and reliability. The method can detect levels of these drugs in urine and water sewage as low as $3.8 \mathrm{nmol} / \mathrm{l}$ and will be applied for prevention of both occupational and environmental toxicity.

\section{REFERENCES}

1. International Agency for Research on Cancer. Cyclophosphamide. In: IARC monographs on the evaluation of the carcinogenic risk of chemicals. Some antineoplastic and 
immunosuppressive agents. Vol. 26. Lyon: The Agency; 1981. p. 165-202.

2. Chabner BA, Allegra CJ, Curt GA, Calabresi P. Antineoplastic agents. In: Hardman JG, Limbird LE, Molinoff PB, Ruddon RW, Gilman AG, editors. Goodman \& Gilmans's the pharmacological basic of therapeutics. 9th ed. New York: McGraw-Hill; 1996. p. 1237-40.

3. Fleming RA. An overview of cyclophosphamide and ifosfamide pharmacology. Pharmacotherapy. 1997;17(5 Pt 2): 146S-54S.

4. Kirshon B, Wasserstrum N, Willis R, Hermam GE, McCabe ER. Teratogenic effects of first-trimester cyclophosphamide therapy. Obstet Gynecol. 1988;72(3 Pt 2):462-4.

5. Connor TH, Lawson CC, Polovich M, McDiarmid MA. Reproductive health risks associated with occupational exposures to antineoplastic drugs in health care settings: A review of the evidence. J Occup Environ Med. 2014;56(9):901-10, http://dx.doi.org/10.1097/JOM.0000000000000249.

6. Hirst M, Tes S, Mills DG, Levin L, White DF. Occupational exposure to cyclophosphamide. Lancet. 1984;28:186-8, http://dx.doi.org/10.1016/S0140-6736(84)92111-1.

7. Sessink PJM, Kroese ED, van Kranen HJ, Bos RP. Cancer risk assessment for health care workers occupationally exposed to cyclophosphamide. Int Arch Occup Environ Health. 1995;67:317-23, http://dx.doi.org/10.1007/BF00385647.

8. Valanis B, Vollmer WM, Steele P. Occupational exposure to antineoplastic agents: Self-reported miscarriages and stillbirths among nurses and pharmacists. J Occup Environ Med. 1999;41(8):632-8, http://dx.doi.org/10.1097/00043764199908000-00004.

9. Buerge IJ, Buser HR, Poiger T, Müller MD. Occurrence and fate of the cytostatic drugs cyclophosphamide and ifosfamide in wastewater and surface waters. Environ Sci Technol. 2006;40:7242-50, http://dx.doi.org/10.1021/es0609405.

10. Sessink PJ, Boer KA, Scheefhals AP, Anzion RB, Bos RP. Occupational exposure to antineoplastic agents at several departments in a hospital. Environmental contamination and excretion of cyclophosphamide and ifosfamide in urine of exposed workers. Int Arch Occup Environ Health. 1992;64(2):105-12, http://dx.doi.org/10.1007/BF 00381477.

11. Baumann F, Lorenz C, Jaehde U, Preiss R. Determination of cyclophosphamide and its metabolites in human plasma by high-performance liquid chromatography-mass spectrometry. J Chromatogr B Biomed Sci Appl. 1999;729:297-305, http://dx.doi.org/10.1016/S0378-4347(99)00178-4.

12. De Jonge ME, van Dam SM, Hillebrand MJ, Rosing H, Huitema $\mathrm{AD}$, Rodenhuis $\mathrm{S}$, et al. Simultaneous quantification of cyclophosphamide, 4-hydroxycyclophosphamide, $N, N$, $N$ "triethylenethiophosphoramide (thiotepa) and $N, N, N$ '-triethylenephosphoramide (tepa) in human plasma by high-performance liquid chromatography coupled with electrospray ionization tandem mass spectrometry. J Mass Spectrom. 2004;39(3):262-71, http://dx.doi.org/10.1002/jms.570.

13. DiFrancesco R, Griggs JJ, Donnelly J, DiCenzo R. Simultaneous analysis of cyclophosphamide, doxorubicin and doxorubicinol by liquid chromatography coupled to tandem mass spectrometry. J Chromatogr B. 2007;852:545-53, http:// dx.doi.org/10.1016/j.jchromb.2007.02.033.

14. Sottani C, Rinaldi P, Leoni E, Poggi G, Teragni C, Delmonte A, et al. Simultaneous determination of cyclophosphamide, ifosfamide, doxorubicin, epirubicin and daunorubicin in human urine using high-performance liquid chromatography/electrospray ionization tandem mass spectrometry: Bioanalytical method validation. Rapid Commun Mass Spectrom. 2008;22:2645-59, http://dx.doi. org/10.1002/rcm.3657.

15. Llewellyn N, Lloyd P, Jürgens MD, Johnson AC. Determination of cyclophosphamide and ifosfamide in sewage effluent by stable isotope-dilution liquid chromatography-tandem mass spectrometry. J Chromatogr A. 2011;1218:8519-28, http://dx.doi.org/10.1016/j.chroma.2011.09.061.

16. Huitema ADR, Tibben MM, Kerbusch T, Zwikker JW, Rodenhuis S, Beijnen JH. Simultaneous determination of $N, N$, $N$ "-triethylenethiophosphoramide, cyclophosphamide and some of their metabolites in plasma using capillary gas 
chromatography. J Chromatogr B Biomed Sci Appl. 1998; 716:177-86, http://dx.doi.org/10.1016/S0378-4347(98)00300-4.

17. Kerbusch T, Jeuken MJ, Derraz J, van Putten JW, Huitema $\mathrm{AD}$, Beijnen JH. Determination of ifosfamide, 2- and 3-dechloroethyifosfamide using gas chromatography with nitrogen-phosphorus or mass spectrometry detection. Ther Drug Monit. 2000;22(5):613-20, http://dx.doi. org/10.1097/00007691-200010000-00018.

18. De Bruijn EA, van Oosterom AT, Leclercq PA, de Haan JW, van de Ven LJ, Tjaden UR. Monitoring the behaviour of 4-ketocyclophosphamide versus cyclophosphamide during capillary gas chromatography by mass spectrometry. Biomed Environ Mass Spectrom. 1987;14(11):643-7, http://dx.doi. org/10.1002/bms.1200141113.

19. Van den Bosch N, de Vos D. Some aspects of the gas-liquid chromatographic analysis of cyclophosphamide in plasma. J Chromatogr B Biomed Sci Appl. 1980;183:49-56, http:// dx.doi.org/10.1016/S0378-4347(00)81397-3.

20. Konieczka P, Namieśnik J. Estimating uncertainty in analytical procedures based on chromatographic techniques. J Chromatogr A. 2010;1217:882-91, http://dx.doi. org/10.1016/j.chroma.2009.03.078.

21. Annesley TM. Ion suppression in mass spectrometry. Clin Chem. 2003;49(7):1041-4, http://dx.doi.org/10. 1373/49.7.1041.
22. Lin DL, Wang SM, Wu CH, Chen BG, Liu RH. Chemical derivatization for the analysis of drugs by GC-MS - A conceptual review. J Food Drug Anal. 2008;16(1):1-10.

23. Zaikin VG, Halket JM. Review: Derivatization in mass spectrometry 2. Acylation. Eur J Mass Spectrom. 2003;9(5):42134, http://dx.doi.org/10.1255/ejms.576.

24. Holdiness MR, Morgan LR Jr. Electron-capture-gas chromatographic analysis of ifosfamide in human plasma and urine. J Chromatogr B Biomed Sci Appl. 1983;275(2):432-5, http://dx.doi.org/10.1016/S0378-4347(00)84392-3.

25. Sugiura S, Asano M, Kinoshita K, Tanimura M, Nabeshima T. Risks to health professionals from hazardous drugs in Japan: A pilot study of environmental and biological monitoring of occupational exposure to cyclophosphamide. J Oncol Pharm Pract. 2010;17(1):14-9, http://dx.doi. org/10.1177/1078155209358632.

26. Sottani C, Tranfo G, Faranda P, Minoia C. Highly sensitive high-performance liquid chromatography/selective reaction monitoring mass spectrometry method for the determination of cyclophosphamide and ifosfamide in urine of health care workers exposed to antineoplastic agents. Rapid Commun Mass Spectrom. 2005;19:2794-800, http://dx.doi. org/10.1002/rcm.2116.

This work is available in Open Access model and licensed under a Creative Commons Attribution-NonCommercial 3.0 Poland License - http://creativecommons.org/ licenses/by-nc/3.0/pl/deed.en. 